\title{
Comparison of adipokines in a
} cross-sectional study with healthy overweight, insulin-sensitive and healthy lean, insulin-resistant subjects, assisted by a family doctor primary care program

Samuel D. Moscavitch ${ }^{1,3^{*}}$, Hye C. Kang ${ }^{2}$, Rubens A. C. Filho ${ }^{3}$, Evandro T. Mesquita ${ }^{3}$, Hugo C. C. F. Neto ${ }^{1}$ and Maria L. G. Rosa ${ }^{4}$

\begin{abstract}
Background: In most individuals, obesity and insulin resistance coexist. However, some individuals have excessive adipose tissue mass but remain insulin sensitive. Moreover, lean individuals can develop acute inflammation-induced insulin resistance, even without excess adipose tissue mass.
\end{abstract}

Objective: Our aim was to compare inflammatory markers in overweight, insulin-sensitive and lean, insulin-resistant healthy subjects.

Methods: A cross-sectional study with 1098 participants (CAMELIA project) was conducted in family doctor primary care program at Niteroi, RJ, Brazil. In the present substudy, we have selected non-obese healthy subjects ( $n=203)$. Insulin resistance was defined by a homeostatic model assessment (HOMA-IR) $>2.6$, and overweight subject BMls were $25<\mathrm{BMI}<30 \mathrm{~kg} / \mathrm{m} 2$. Associations were estimated through binary logistic regression with generalized estimation equation models.

Results: We compared overweight, insulin-sensitive healthy individuals $(n=74)$ with a mean age of $39.2 \pm 1.3$ and lean, insulin-resistant healthy individuals $(n=18)$ with a mean age of 31.9 \pm 3.6 . C-reactive protein levels were positively correlated with body mass index in the lean, insulin-resistant group. In the multiple regression model, a positive association was observed with MCP-1 and IL-6 expression after adjustment for age, waist circumference, glycated hemoglobin, resistin, adiponectin, C-reactive protein and PAI-1 levels.

Conclusion: Our findings suggest that a lean, insulin-resistant subject may have higher pro-inflammatory marker levels (MCP-1, IL-6 and resistin) than an overweight, insulin-sensitive subject. This suggest an early risk phenotype that should further be investigated for possible prognostic implications.

Keywords: Adiponectin, Obesity, Lean, Insulin resistance, Inflammation, HOMA, BMI, Cytokine, C reactive protein, Adipokines

\footnotetext{
*Correspondence: samuel.moscavitch@ioc.fiocruz.br

${ }^{1}$ Laboratory of Immunopharmacology, Oswaldo Cruz Institute (IOC),

Avenue Brasil 4365, Manguinhos, Rio de Janeiro 21045-900, Brazil

Full list of author information is available at the end of the article
} 


\section{Background}

During the last century, epidemiologic studies have suggested a possible relationship between inflammation and insulin resistance [1]. More recently, this evidence has become robust and suggests that obesity and inflammation are the main components of insulin resistance $[2,3]$. The adipose tissue is directly involved in the inflammatory response and produces several cytokines, such as adiponectin, resistin, interleukin-6 (IL-6), plasminogen activator inhibitor-1 (PAI-1) and monocyte chemotactic protein-1 (MCP-1). Excess adipose tissue also promotes inflammation, which is accompanied by monocyte and $B$ and $T$ lymphocyte infiltration [4]. Chronic inflammatory state in obesity is maintained by interactions between leptin and inflammation, where an increase on pro-inflammatory cytokines leads to leptin release. In most individuals, insulin resistance and obesity coexist. However, some subjects with excessive body fat have better insulin sensitivity than expected for their adiposity [5]. Conversely, lean subjects can develop inflammationassociated insulin resistance [6].

Despite the importance of inflammation, studies comparing the individual impacts of obesity and insulin resistance on inflammatory activation are not found in the literature. This comparison will expand our knowledge concerning the complex dynamics of inflammation, adiposity and insulin resistance.

Our aim was to describe and compare inflammatory markers in overweight, insulin-sensitive and lean, insulin-resistant subjects, assisted by a family doctors primary care program.

\section{Methods}

The Cardio-neuro-Metabolic-renal Familial (CAMELIA) project is a transverse observational study with 1098 participants in which cardiologists, neurologists, psychiatrists, endocrinologists, nephrologists, general doctors, nutritionists, nurses and students participated; this project aimed to study cardiovascular risk factors and related issues, such as familial aggregation. This project was conducted between July 2006 and December 2007 in 13 modules of the Family Doctors Program of Niteroi, RJ, Brazil, which was selected in an attempt to include all of the politico-administrative regions of the city. Data collection (demographic, anthropometric, clinical, psychological, nutritional, and blood and urine samples) was performed during project visits to each regional family doctor clinic (to assess more detailed CAMELIA project information, see Ref. [7]). The insulin, PAI-1, MCP1 , resistin, adiponectin and IL- 6 were analyzed on a Luminex ${ }^{\circledR}$. C reactive protein (CRP) was analyzed using an ELISA commercial kit. The sample criteria selection for this substudy aimed to include healthy subjects, without any comorbidity. We included those who were older than 18 years; did not have any cardiovascular diseases (myocardial infarction, heart failure, cerebrovascular accident); were not under medication for hypertension, diabetes, or hyperlipidemia; had a BMI (body mass index) $<30 \mathrm{~kg} / \mathrm{m}^{2}$; and had no previous diagnosis of diabetes. Overweight was defined as having a BMI $25<\mathrm{BMI}<30 \mathrm{~kg} / \mathrm{m}^{2}$ [8]. Insulin resistance was defined as a homeostatic model assessment (HOMA-IR) $>2.6$ [9-11]. From among these subjects, we have selected 203 subjects and separated into 4 groups: (a) normal BMI subjects $\left(<25 \mathrm{~kg} / \mathrm{m}^{2}\right)$ with preserved insulin sensitivity; (b) normal BMI subjects $\left(<25 \mathrm{~kg} / \mathrm{m}^{2}\right)$ with insulin resistance (c) overweight subjects with preserved insulin sensitivity; (d) overweight subjects with insulin resistance. After analysis, we finally selected 92 non-obese healthy subjects and separated them into 2 groups: (I) normal BMI subjects $\left(<25 \mathrm{~kg} / \mathrm{m}^{2}\right)$ with insulin resistance $(\mathrm{n}=18)$, OW(-)IR(+); (II) overweight subjects with preserved insulin sensitivity $(\mathrm{n}=74)$, OW $(+) \operatorname{IR}(-)$.

Parametric variables were analyzed with Student's $t$ test, and non-parametric variables were analyzed with the Spearman test correlation. Univariate parametric (Student's T) and non-parametric (Mann-Whitney) tests were used to investigate potential differences between the groups. For generalized estimated equations (GEE), binary logistic regressions were performed with variables that reached $p$ values $<0.150$ on parametric and non-parametric tests and included cytokines and variables related to adiposity and glucose metabolism. Statistical analysis was performed using SPSS Statistics $17^{\circledR}$ software. The data were statistically significant at $\mathrm{p}<0.05$. The CAMELIA study protocol was approved by the Federal Fluminense University Ethics Committee (UFF/Huap\#220/05), and all of the patients signed written consent forms.

\section{Results}

In the OW(+)IR(-) group, the mean age was $39.2 \pm 1.3$, and 49 were female $(66.2 \%)$, and in the OW(-)IR(+) group, the mean age was $31.9 \pm 3.6$, and 12 were female (66.7\%). Demographic, anthropometric and biochemical variables are listed in Table 1 . The variables that exhibited differences between the groups were age, skin color and high-risk abdominal circumference. The non-parametric analysis is shown in Table 2. Lean, insulin-resistant subjects $[\mathrm{OW}(-) \mathrm{IR}(+)$ group] had significantly higher MCP-1 and IL-6 levels and a lower prevalence of high-risk waist circumference, compared with overweight non-insulin resistant group. Multivariate analysis by GEE showed that the presence of insulin resistance was associated with increased MCP-1 (OR = 1.005, p = 0.007) and IL-6 levels $(\mathrm{OR}=1.263, \mathrm{p}=0.026)$ and with reduced adiponectin levels $(O R=0.893, p=0.033)$ after adjustment for 
Table 1 Demographic, anthropometric and laboratorial data, according to presence of overweight $(n=74)$ or insulin resistance $(n=18)$

\begin{tabular}{|c|c|c|c|}
\hline & $\mathrm{OW}(+) \operatorname{IR}(-)$ & $O W(-) I R(+)$ & $p$ value \\
\hline \multicolumn{3}{|l|}{ Gender } & 1,000 \\
\hline Female & $49(66.2)$ & $12(66.7)$ & \\
\hline Male & $25(33.8)$ & $6(36.8)$ & \\
\hline \multicolumn{3}{|l|}{ Age } & $<0.001$ \\
\hline$<20$ years & $1(1.4)$ & $7(38.9)$ & \\
\hline $20-29$ & $17(23.0)$ & $4(22.2)$ & \\
\hline $30-39$ & $19(25.7)$ & $1(5.6)$ & \\
\hline $40-49$ & $28(37.8)$ & $3(16.7)$ & \\
\hline $50-59$ & $7(9.5)$ & $3(16.7)$ & \\
\hline 60 out & $2(2.7)$ & $0(5.3)$ & \\
\hline \multicolumn{3}{|l|}{ Skin color } & 0.016 \\
\hline Black or mulatto & $59(78.7)$ & $9(50.0)$ & \\
\hline White & $15(20.3)$ & $9(50.0)$ & \\
\hline \multicolumn{3}{|l|}{ Total cholesterol } & 0.276 \\
\hline$<200 \mathrm{mg} / \mathrm{dL}$ & $46(62.2)$ & $14(77.8)$ & \\
\hline$\geq 200 \mathrm{mg} / \mathrm{dL}$ & $28(37.8)$ & $4(22.2)$ & \\
\hline \multicolumn{3}{|l|}{$\mathrm{HDL}-\mathrm{C}^{\mathrm{a}}$} & 0.603 \\
\hline Normal & $39(52.7)$ & $11(61.1)$ & \\
\hline Elevated & $35(47.3)$ & $7(38.9)$ & \\
\hline \multicolumn{3}{|l|}{ Triglycerides } & 0.404 \\
\hline$<150 \mathrm{mg} / \mathrm{dL}$ & $67(90.5)$ & $15(83.3)$ & \\
\hline$\geq 150 \mathrm{mg} / \mathrm{dL}$ & $7(9.5)$ & $3(16.7)$ & \\
\hline \multicolumn{3}{|l|}{ Uric acid ${ }^{b}$} & 0.251 \\
\hline Normal & $71(95.9)$ & $15(88.9)$ & \\
\hline Elevated & $3(4.1)$ & $2(11.1)$ & \\
\hline \multicolumn{3}{|l|}{ Blood pressure } & 0.529 \\
\hline Normal & $59(79.7)$ & $13(72.2)$ & \\
\hline Hypertension & $15(20.3)$ & $5(27.8)$ & \\
\hline \multicolumn{3}{|c|}{ Abdominal circumference } & 0.027 \\
\hline Normal & $45(60.8)$ & $16(88.9)$ & \\
\hline High-risk & 29 (39.2) & $2(11.1)$ & \\
\hline
\end{tabular}

a Normal HDL-C: $\geq 40 \mathrm{mg} / \mathrm{dL}$ for men or $\geq 50 \mathrm{mg} / \mathrm{dL}$ for women

b Elevated Uric Acid: $>6.8 \mathrm{mg} / \mathrm{dL}$ for men and $>6 \mathrm{mg} / \mathrm{dL}$ for women Variables wtih $p$ values $<0.150$ were selected for logistic binary modeling Statistical significance was considered as $p<0.05$ (in italics)

skin color, age, waist circumference and glycated hemoglobin (Table 3, model 1). In model 2 (Table 3), all of the studied cytokines were included, skin color and glycated hemoglobin were excluded. Model 2 (Table 3) shows that presence of insulin resistance was positively associated with MCP-1 (OR $=1.005, \mathrm{p}=0.024)$ and IL-6 levels; and, negatively associated with CRP levels $(\mathrm{OR}=0.989$, $\mathrm{p}=0.049$ ). In model 3 (Table 3 ), glycated hemoglobin was included, waist circumference was excluded. Model 3 (Table 3) shows that presence of insulin resistance was positively associated with resistin $(\mathrm{OR}=1.017, \mathrm{p}=0.001)$,
IL-6 $(\mathrm{OR}=1.393, \mathrm{p}=0.002)$ and glycated hemoglobin $(\mathrm{OR}=3.332, \mathrm{p}=0.036)$ and negatively associated with age (OR $=0.921, \mathrm{p}=0.024)$ and PAI-1 levels $(\mathrm{OR}=0.981$, $\mathrm{p}=0.017)$. Waist circumference was included in model 4 (Table 3), in which it was observed that presence of insulin resistance was positively associated with MCP-1 $(\mathrm{OR}=1.006, \mathrm{p}=0.024)$ and IL6 levels $(\mathrm{OR}=1.361$, $\mathrm{p}=0.016$ ), which were stronger than in the previous models 1 and 2. As shown in Figs. 1, 2, CRP levels presented a positive correlation with BMI $(\mathrm{r}=0.695, \mathrm{p}=0.001)$ and waist circumference $(\mathrm{r}=0.628, \mathrm{p}=0.005)$ in $\mathrm{OW}(-) \operatorname{IR}(+)$ group. Conversely, in OW(+)IR(-) group, BMI presented negative correlation with IL-6 $(\mathrm{r}=-0.245, \mathrm{p}=0.036)$ and MCP-1 levels $(r=-0.269, p=0.020)$, as seen, respectively, in Figs. 3, 4.

\section{Discussion}

In the present study, lean, insulin-resistant subjects presented a more inflammatory profile than overweight, insulin-sensitive subjects. Several studies have demonstrated that obesity promotes a chronic inflammatory state that is associated with inflammatory macrophage infiltration and accumulation in adipose tissue and that contributes to the development of insulin resistance and diabetes [12-15]. However, obesity per se is not a precondition for the development of insulin resistance but, rather, the degree of adipose tissue inflammation [4].

The local action of cytokines such as TNF-a on adipocytes was one of the first pieces of evidence suggesting a possible link between insulin resistance and pathogenic inflammatory processes [16]. Although adiposity is closely related to inflammation, our findings suggest that lean, insulin-resistant individuals could present higher levels of inflammatory biomarker even without excessive adipose tissue, compared with an overweight subject without insulin resistance. When endotoxemia was induced in healthy subjects, the acute inflammation was capable of modulating the signaling and inflammatory pathways in adipose tissue, thus causing insulin resistance, without an increase on adiposity [6]. Resistin is a pro-inflammatory cytokine that can promote systemic insulin resistance when injected in mice $[1,17]$. Although this effect is supported by strong animal study evidences, the human-related data are less consistent $[18,19]$. In our study, multivariate analysis indicated that lean, insulin-resistant subjects presented higher resistin levels $(\mathrm{OR}=1.017, \mathrm{p}=0.001)$ compared with $\mathrm{OW}(+) \mathrm{IR}(-)$ subjects after adjustment for age, IL-6, MCP-1, CRP, adiponectin and glycated hemoglobin levels (Table 3, model 3 ). The same association remained strong in models adjusted for waist circumference (Table 3, models 2, 4). Additionally, resistin-deficient ob/ob mice, even with an increased body adiposity, have normal glucose tolerance 
Table 2 Mann-Whitney Test for non-parametric variables, according to presence of overweight $(n=74)$ or insulin resistance $(\mathbf{n}=\mathbf{1 8})$

\begin{tabular}{|c|c|c|c|}
\hline & OW(+)IR(-) (mean-rank) & $O W(-) I R(+)$ (mean-rank) & P value \\
\hline Age & 49.88 & 32.61 & 0.014 \\
\hline \multicolumn{4}{|l|}{ Circumference } \\
\hline Waist & 53.05 & 19.58 & $<0.001$ \\
\hline Abdominal & 52.72 & 20.94 & $<0.001$ \\
\hline Glycated hemoglobin & 43.86 & 54.67 & 0.120 \\
\hline \multicolumn{4}{|l|}{ Cytokines } \\
\hline $\mathrm{C}$ reactive protein & 47.80 & 41.17 & 0.345 \\
\hline$M C P-1^{a}$ & 43.34 & 59.50 & 0.021 \\
\hline $1 \mathrm{~L}-6^{\mathrm{b}}$ & 43.42 & 59.17 & 0.025 \\
\hline Resistin & 44.95 & 52.89 & 0.258 \\
\hline Adiponectin & 43.95 & 56.97 & 0.063 \\
\hline $\mathrm{PAl}-1^{\mathrm{C}}$ & 46.41 & 46.86 & 0.949 \\
\hline
\end{tabular}

a Macrophage Chemoattractant Protein-1

b Interleukin-6

c Plasminogen activator inhibitor-1

Variables wtih $p$ values $<0.150$ were selected for logistic binary modeling

Statistical significance was considered as $p<0.05$ (in italics)

Table 3 Adjusted logistic regression models, according to presence of insulin resistance $[\mathrm{OW}(-) \operatorname{IR}(+)]$ or absence $[\mathrm{OW}(+) \operatorname{IR}(-)]$

\begin{tabular}{|c|c|c|c|c|}
\hline & $\begin{array}{l}\text { Model } 1 \\
\text { OR (95 \%) }\end{array}$ & $\begin{array}{l}\text { Model } 2 \\
\text { OR (95 \%) }\end{array}$ & $\begin{array}{l}\text { Model } 3 \\
\text { OR (95 \%) }\end{array}$ & $\begin{array}{l}\text { Model } 4 \\
\text { OR (95\%) }\end{array}$ \\
\hline Age & $1.083(0.925-1.268)$ & $1.064(0.940-1.205)$ & $0.921(0.858-0.989)^{*}$ & $1.049(0.898-1.225)$ \\
\hline $\mathrm{MCP}-1^{\mathrm{a}}$ & $1.005(1.001-1.008)^{* *}$ & $1.005(1.001-1.010)^{*}$ & $1.003(0.999-1.006)$ & $1.006(1.001-1.011)^{*}$ \\
\hline $\mathrm{C}$ reactive protein & - & $0.989(0.979-1.000)^{*}$ & $0.984(0.966-1.003)$ & $0.992(0.976-1.008)$ \\
\hline$I L-6^{b}$ & $1.263(1.029-1.551)^{*}$ & $1.361(1.060-1.747)^{*}$ & $1.393(1.133-1.713)^{* *}$ & $1.390(1.106-1.746)^{* *}$ \\
\hline Resistin & - & $1.016(1.000-1.033)$ & $1.017(1.010-1.025)^{* *}$ & $1.015(0.997-1.034)$ \\
\hline $\mathrm{PAl}-1^{\mathrm{C}}$ & - & $0.993(0.976-1.009)$ & $0.981(0.966-0.997)^{*}$ & $0.985(0.961-1.011)$ \\
\hline Adiponectin & $0.893(0.804-0.991)^{*}$ & $0.868(0.727-1.037)$ & $1.012(0.978-1.048)$ & $0.919(0.741-1.139)$ \\
\hline Waist circumf & $0.653(0.471-0.905)^{*}$ & $0.676(0.514-0.888)^{* *}$ & - & $0.693(0.532-0.903)^{* *}$ \\
\hline Glycated Hb & $1.978(0.813-4.814)$ & - & $3.332(1.079-10.293)^{*}$ & $2.575(0.481-13.801)$ \\
\hline White & $0.457(0.089-2.274)$ & - & - & - \\
\hline Mulatto or black & 1 & - & - & - \\
\hline
\end{tabular}

Binary logistic model adjusted by GEE-In model 1, the variables included were that reached $\mathrm{p}$ value $<0.150$ on parametric and non-parametric tests (Tables 1 and 2). In model 2, all cytokines and a variable related to overweight were included. In model 3, all cytokines and a variable related to glucose metabolic imbalance were included, and waist circumference was excluded. In model 4, all cytokines, a variable related to glucose metabolic imbalance and a variable related to overweight were included

a Macrophage Chemoattractant Protein-1

b Interleukin-6

c Plasminogen activator inhibitor-1

* $p$ value $<0.050$

** p value $<0.010$

Statistical significance was considered as $p<0.05$ (in italics)

and preserved insulin sensitivity [20]. This suggests that resistin is a key player on the induction of insulin resistance and it is closely related to it.

MCP-1 is a cytokine that activates cells from the monocytic lineage, enhances $\mathrm{CD} 11 \mathrm{~b} / \mathrm{CD} 18$ expression, and increases pro-inflammatory cytokines in human endotoxemia model [21, 22]. A recent study on transgenic mice demonstrated that MCP-1 overexpression in visceral adipose tissue resulted in elevated plasma MCP-1 levels and robust inflammatory macrophage recruitment that 

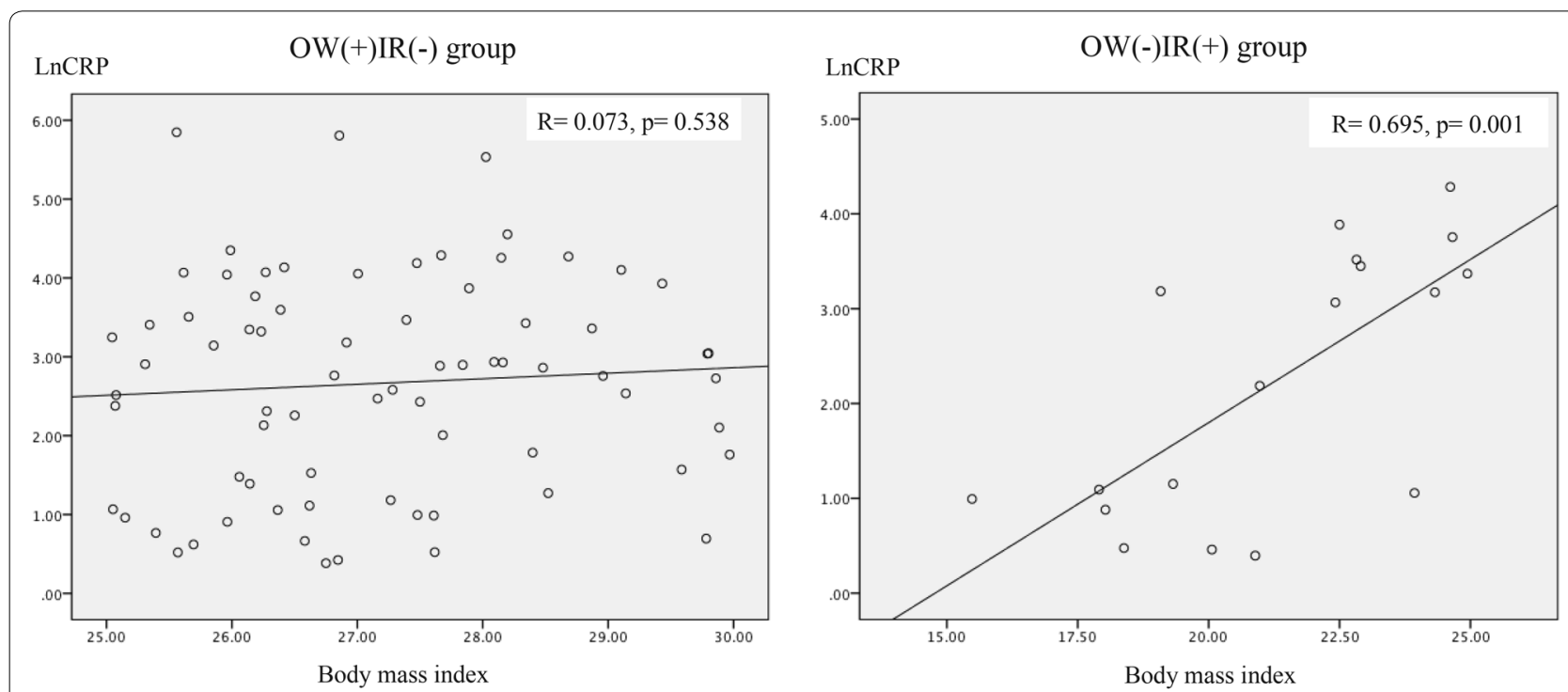

Fig. 1 Correlation between $\mathrm{C}$ reactive protein and body mass index, according to the presence of overweight $(n=74)$ or insulin resistance $(n=18)$
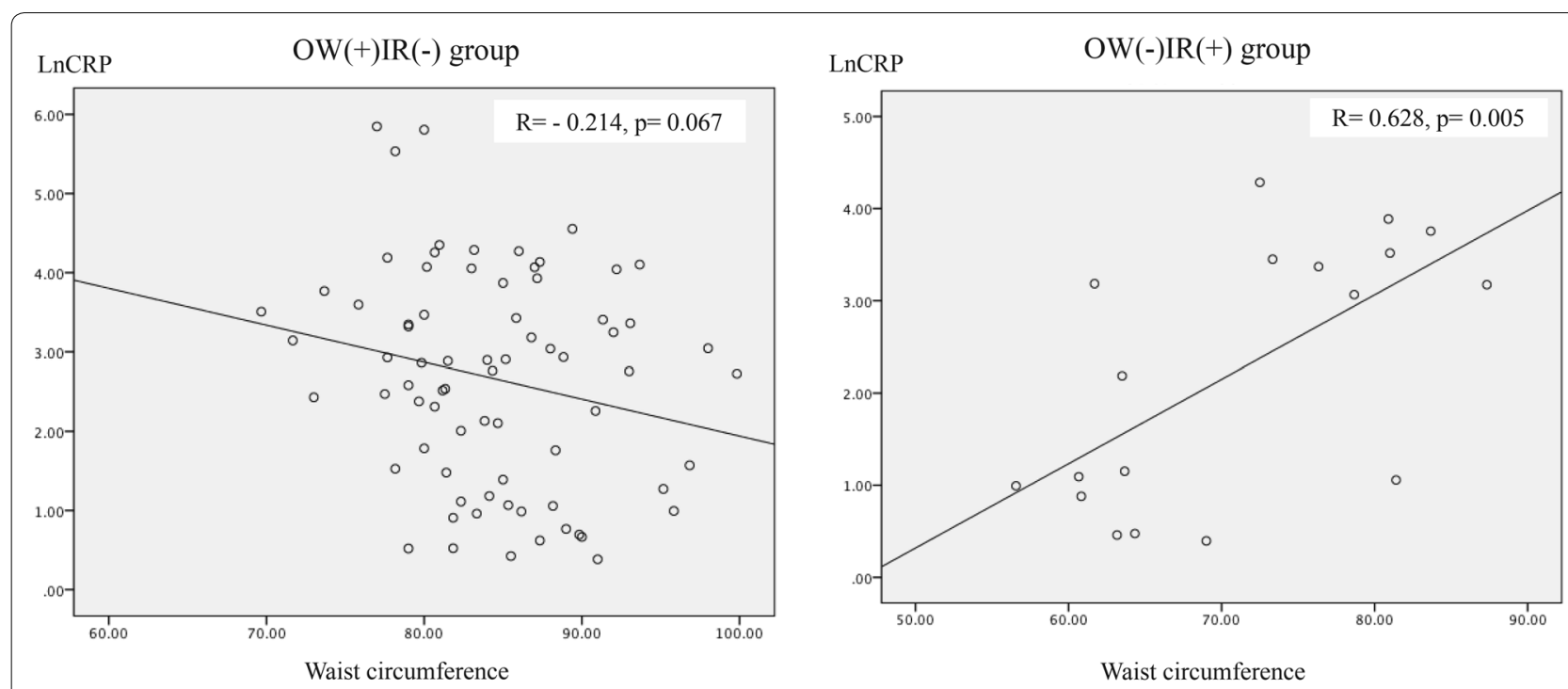

Fig. 2 Correlation between C reactive protein and waist circumference, according to presence of overweight $(n=74)$ or insulin resistance $(n=18)$

caused systemic insulin resistance [23]. Additionally, adipose tissue macrophages contribute significantly to the elevation of cytokine levels, such as TNF-a and IL-6 [13, 24]. IL-6 was one of the first pro-inflammatory cytokines to be implicated in insulin resistance pathogenesis and as a cardiovascular risk factor. Diabetic patients present high levels of serum IL-6 [25]. In our study, lean, insulin-resistant subjects had higher IL-6 $(\mathrm{OR}=1.263, \mathrm{p}=0.026)$ and MCP-1 levels $(\mathrm{OR}=1.005, \mathrm{p}=0.007)$ than OW(+)IR $(-)$ patients (Table 3, model 1). After adjustment for age, waist circumference, resistin, CRP, PAI-1, adiponectin and glycated hemoglobin levels, the association of having insulin resistance and higher levels of IL-6 $(\mathrm{OR}=1.390$, $\mathrm{p}=0.005)$ and MCP-1 (OR $=1.006, \mathrm{p}=0.026)$ became stronger (Table 3, model 4). Conversely, in an interesting Japanese study, increased visceral fat mass, as measured by tomography, was an independent predictor for the elevation of CRP levels in individuals with mild obesity or reduced glucose tolerance [26]. This is Japanese study also showed, with multiple linear regression, that visceral fat exhibited a higher correlation to CRP levels [26]. Similarly, in our present study, CRP levels had presented a strong 

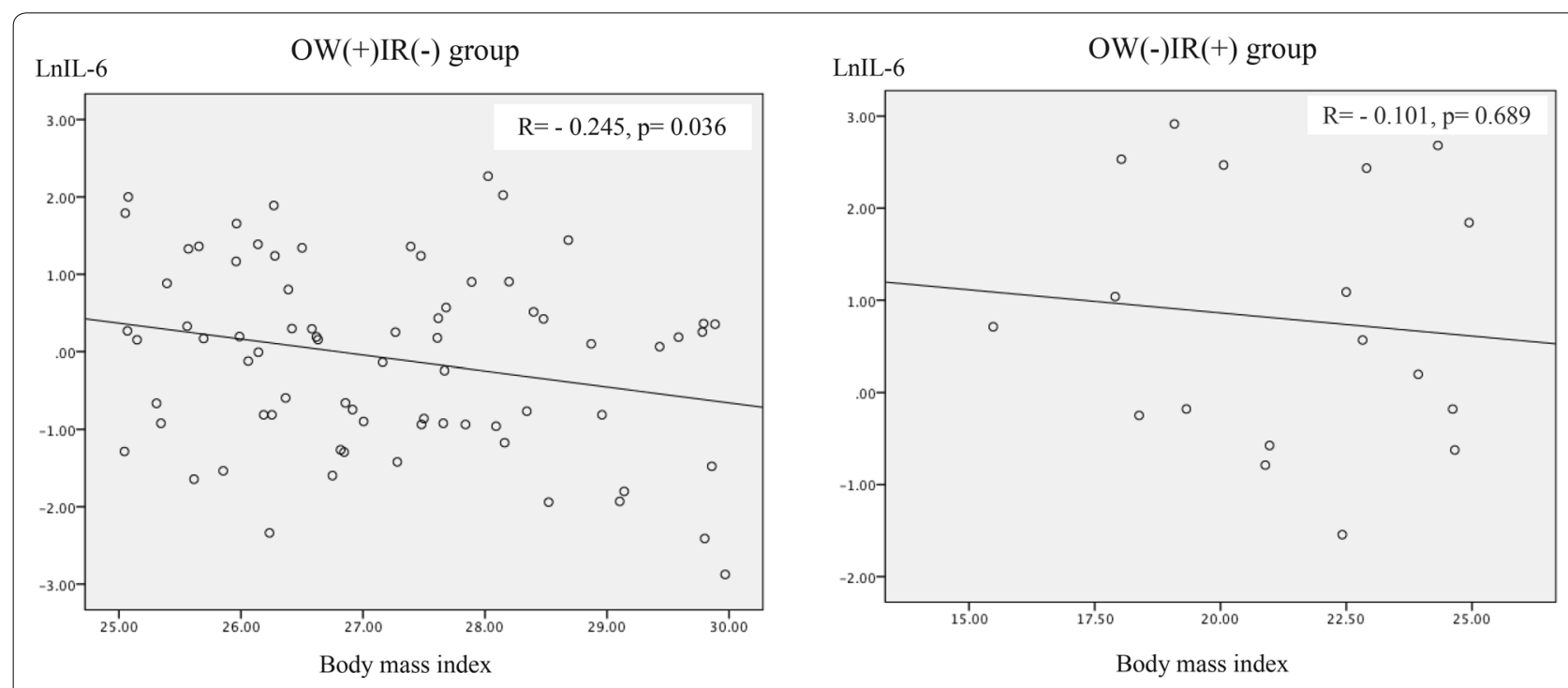

Fig. 3 Correlation between interleukin-6 and body mass index, according to presence of overweight $(n=74)$ or insulin resistance $(n=18)$

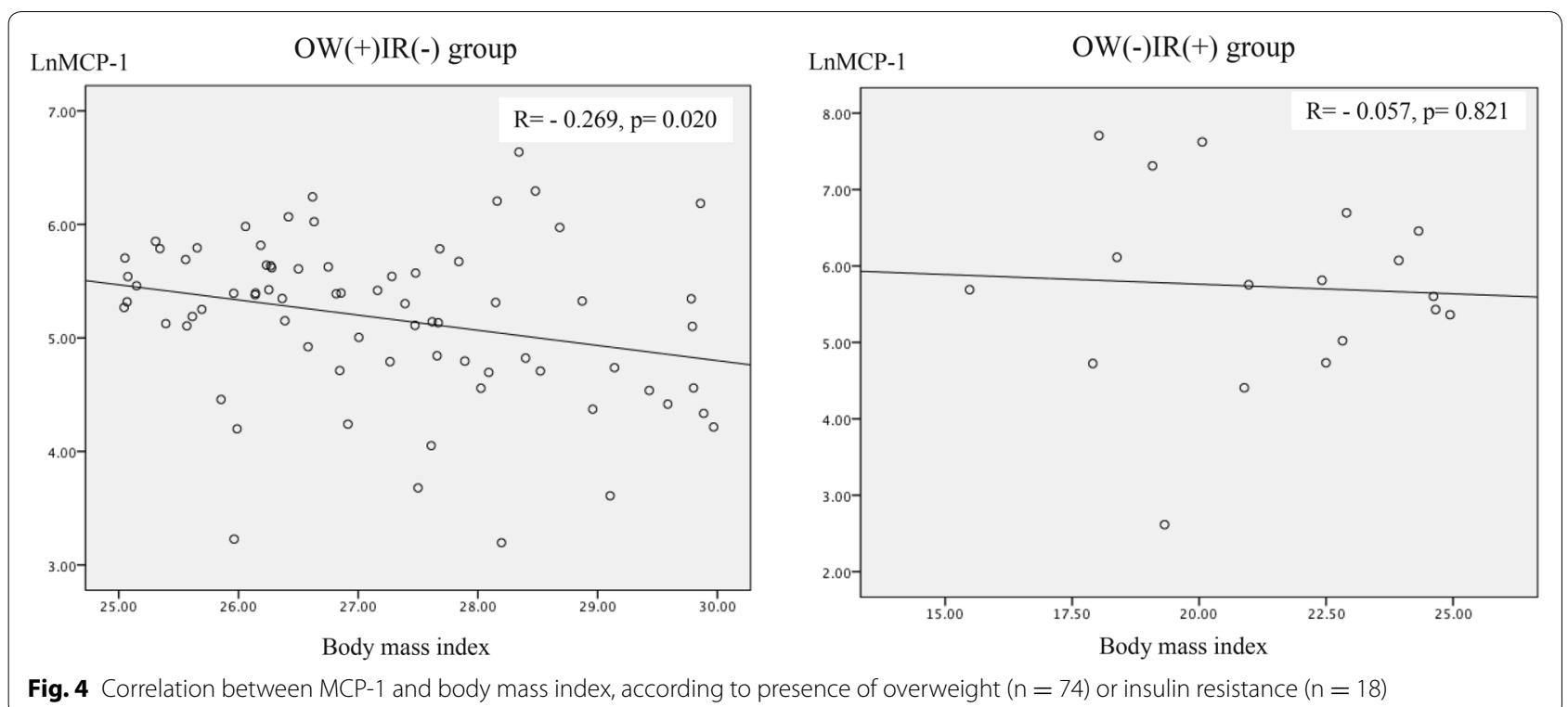

correlation with BMI $(\mathrm{r}=0.695, \mathrm{p}=0.001)$ and waist circumference $(r=0.628, p=0.005)$ in the lean, insulin resistant group, as seen in Figs. 1, 2. However, these correlations were not found in the $\mathrm{OW}(+) \mathrm{IR}(-)$ group. Additionally, the OW(+)IR(-) subjects had higher CRP levels according to logistic regression $(\mathrm{OR}=0.989, \mathrm{p}=0.049)$ compared with the $\mathrm{OW}(-) \operatorname{IR}(+)$ group, independent of age, waist circumference, IL-6, MCP-1, resistin, PAI-1 and adiponectin levels (Table 3, model 2).

The association between abdominal obesity and increased circulating PAI-1 levels was first described more than 20 years ago $[27,28]$. More recently, it has been proposed that adipose tissue directly contributes to increased PAI-1 levels in obesity [29, 30]. Several interventional studies have demonstrated that a significant reduction in PAI-1 levels occurs after obese people lose weight through diet [31,32] or jejunoileal bypass surgery [33]. Additionally, the reduced PAI-1 levels associated with losing weight is suggested to be related to the amount of weight lost and not to metabolic changes, such as variations on insulin or triglyceride levels [31, 32]. In our study, multivariate regression demonstrated 
that $\mathrm{OW}(+) \mathrm{IR}(-)$ subjects had higher PAI-1 levels than the lean, insulin-resistant group $(\mathrm{OR}=0.981, \mathrm{p}=0.017)$, independent of age, cytokine levels and glycated hemoglobin (Table 3, model 3). However, when the statistical models were adjusted for waist circumference, this association got weaker (Table 3, models 2,4 ), which it is explained by the close relationship between PAI-1 and adiposity.

In contrast to other cytokines, adiponectin has antiinflammatory, anti-apoptotic, and pro-angiogenic effects and is capable of enhancing insulin sensitivity on tissues [34, 35]. Reduced adiponectin levels are detected in diabetes, hypertension and coronary arterial disease, even when adjusted for BMI. Complementarily, insulin resistance diminished when hypoadiponectinemia is normalized by treatment with recombinant adiponectin in a type-2 diabetes animal model [36]. Interestingly, in a study of Pima Indians, who have high prevalence of type-2 diabetes, subjects with high adiponectin levels were found to be less likely to develop diabetes than those with low concentrations, which suggests a protective effect [37]. In our study, the multivariate regression revealed that the $\mathrm{OW}(+) \operatorname{IR}(-)$ group had higher adiponectin levels compared with the OW(-)IR(+) group $(\mathrm{OR}=0.893, \mathrm{p}=0.027)$, independent of age, waist circumference, skin color, IL-6, MCP-1, and glycated hemoglobin levels (Table 3 , model 1). This finding is highly interesting because adiponectin levels are usually inversely related to BMI, waist circumference, body fat percentage and insulin resistance; however, in our study, adiponectin levels were higher in overweight subjects than in insulin-resistant subjects.

Obese or overweight but metabolically healthy individuals continue to represent a challenging phenotype. However, possible explanations reside in interpersonal differences in body fat distribution; life habits, such as physical activity; and metabolic dynamics of adipose tissue balance [38]. A recent study demonstrated that for the same degree of severe obesity, individuals with reduced adipose tissue inflammation exhibited an "intermediate" clinical phenotype with arterial function similar to that of normal weight subjects [39]. This evidence suggests that the exclusively overweight subjects (without insulin resistance) in our study represent a metabolically healthy phenotype with reduced inflammatory activity (lower cytokine and higher adiponectin levels) despite excess adipose tissue. Additionally, OW(+)IR(-) subjects had an inverse correlation of waist circumference with IL-6 levels $(r=-0.245, p=0.036)$. Cytokines that are closely related to adiposity (PAI-1 and CRP) were increased in the overweight group despite lower levels of the other cytokines (IL-6, MCP-1 and resistin) (Table 3).
The limitations of our study were its sample size and selection criteria; HOMA-IR was utilized to identify insulin resistance, although it is not the gold standard for diagnosis, and BMI, despite its prevalence, is not the most trusted index for estimating obesity. Although, BMI has a high and independent association with the risk of incidence of type II diabetes [40]. The impact of the latter is considered to be reduced by other adjusting factors, such as inflammatory markers, waist, abdominal and hip circumferences.

\section{Conclusion}

Our findings suggest that an individual with normal BMI and a HOMA index greater than 2.6 has a significantly higher probability of presenting elevated levels of proinflammatory biomarkers (MCP-1, IL-6 and resistin) than an overweight subject with a HOMA index less than 2.6. More studies are necessary to clarify and extend the understanding of this complex syndrome.

\section{Authors' contributions}

SDM participated in data collection, conducted statistical analyses, performed the cytokines analysis and drafted the manuscript. MLGR designed the study, coordinated the study and conducted statistical analyses. HKC participated in data collection and carried out laboratory analysis. ETM developed the study concept, designed the study and interpreted the data. RACF developed the study concept and interpreted the data. HCCFN performed the cytokines analysis and helped to draft the manuscript. All authors read and approved the final manuscript.

\section{Author details}

${ }^{1}$ Laboratory of Immunopharmacology, Oswaldo Cruz Institute (IOC), Avenue Brasil 4365, Manguinhos, Rio de Janeiro 21045-900, Brazil. ${ }^{2}$ Pathology, Federal Fluminense University, Niteroi, Brazil. ${ }^{3}$ Clinical Medicine, Federal Fluminense University, Niteroi, Brazil. ${ }^{4}$ Epidemiology and Biostatistics, Federal Fluminense University, Niteroi, Brazil.

\section{Competing interests}

The authors declare that they have no competing interests.

Received: 11 June 2015 Accepted: 25 January 2016

Published online: 09 February 2016

\section{References}

1. Ouchi N, Parker JL, Lugus JJ, Walsh K. Adipokines in inflammation and metabolic disease. Nat Rev Immunol. 2011;11:85-97.

2. Luna-Luna M, Medina-Urrutia A, Vargas-Alarcon G, Coss-Rovirosa F, Vargas-Barron J, Perez-Mendez O. Adipose tissue in metabolic syndrome: Onset and Progression of Atherosclerosis. Arch Med Res. 2015;46:392-407.

3. Jung UJ, Choi MS. Obesity and its metabolic complications: the role of adipokines and the relationship between obesity, inflammation, insulin resistance, dyslipidemia and nonalcoholic fatty liver disease. Int J Mol Sci. 2014;15:6184-223.

4. Hamada M, Abe M, Miyake T, et al. B cell-activating factor controls the production of adipokines and induces insulin resistance. Obesity (Silver Spring). 2011;19:1915-22.

5. Samocha-Bonet D, Chisholm DJ, Tonks K, Campbell LV, Greenfield JR. Insulin-sensitive obesity in humans - a 'favorable fat' phenotype? Trends Endocrinol Metab. 2012;23:116-24.

6. Mehta NN, McGillicuddy FC, Anderson PD, et al. Experimental endotoxemia induces adipose inflammation and insulin resistance in humans. Diabetes. 2010;59:172-81. 
7. de Miranda Chagas SV, Kanaan S, Chung Kang H, et al. Environmental factors, familial aggregation and heritability of total cholesterol, low density lipoprotein-cholesterol and high density lipoprotein-cholesterol in a Brazilian population assisted by the Family Doctor Program. Public Health. 2011;125:329-37.

8. de Onis M, Habicht JP. Anthropometric reference data for international use: recommendations from a World Health Organization Expert Committee. Am J Clin Nutr. 1996;64:650-8.

9. Balkau B, Charles MA. Comment on the provisional report from the WHO consultation. European Group for the Study of Insulin Resistance (EGIR). Diabet Med. 1999;16:442-3.

10. Motta M, Bennati E, Ferlito L, Passamonte M, Malaguarnera M. Insulinresistance (IR) in older age. Arch Gerontol Geriatr. 2008;46:203-9.

11. Garmendia ML, Lera L, Sanchez H, Uauy R. Albala C [Homeostasis model assessment (HOMA) values in Chilean elderly subjects]. Rev Med Chil. 2009;137:1409-16.

12. Xu H, Barnes GT, Yang Q, et al. Chronic inflammation in fat plays a crucial role in the development of obesity-related insulin resistance. J Clin Invest. 2003;112:1821-30.

13. Weisberg SP, McCann D, Desai M, Rosenbaum M, Leibel RL, Ferrante AW $J$ r. Obesity is associated with macrophage accumulation in adipose tissue. J Clin Invest. 2003;112:1796-808.

14. Lumeng CN, Bodzin JL, Saltiel AR. Obesity induces a phenotypic switch in adipose tissue macrophage polarization. J Clin Invest. 2007;117:175-84.

15. DeMarco VG, Johnson MS, Whaley-Connell AT, Sowers JR. Cytokine abnormalities in the etiology of the cardiometabolic syndrome. Curr Hypertens Rep. 2010;12:93-8.

16. Hotamisligil GS, Shargill NS, Spiegelman BM. Adipose expression of tumor necrosis factor-alpha: direct role in obesity-linked insulin resistance. Science. 1993;259:87-91.

17. Steppan CM, Bailey ST, Bhat S, et al. The hormone resistin links obesity to diabetes. Nature. 2001;409:307-12.

18. Heilbronn LK, Rood J, Janderova L, et al. Relationship between serum resistin concentrations and insulin resistance in nonobese, obese, and obese diabetic subjects. J Clin Endocrinol Metab. 2004;89:1844-8.

19. Lee $J H$, Chan JL, Yiannakouris N, et al. Circulating resistin levels are not associated with obesity or insulin resistance in humans and are not regulated by fasting or leptin administration: cross-sectional and interventional studies in normal, insulin-resistant, and diabetic subjects. J Clin Endocrinol Metab. 2003;88:4848-56.

20. Qi Y, Nie Z, Lee YS, et al. Loss of resistin improves glucose homeostasis in leptin deficiency. Diabetes. 2006;55:3083-90.

21. Jiang Y, Beller DI, Frendl G, Graves DT. Monocyte chemoattractant protein-1 regulates adhesion molecule expression and cytokine production in human monocytes. J Immunol. 1992;148:2423-8.

22. Zisman DA, Kunkel SL, Strieter RM, et al. MCP-1 protects mice in lethal endotoxemia. J Clin Invest. 1997;99:2832-6.

23. Kamei N, Tobe K, Suzuki R, et al. Overexpression of monocyte chemoattractant protein-1 in adipose tissues causes macrophage recruitment and insulin resistance. J Biol Chem. 2006;281:26602-14.

24. Kim JH, Bachmann RA, Chen J. Interleukin- 6 and insulin resistance. Vitam Horm. 2009;80:613-33.
25. Muller S, Martin S, Koenig W, et al. Impaired glucose tolerance is associated with increased serum concentrations of interleukin 6 and co-regulated acute-phase proteins but not TNF-alpha or its receptors. Diabetologia. 2002;45:805-12.

26. Tsuriya D, Morita H, Morioka T, et al. Significant correlation between visceral adiposity and high-sensitivity C-reactive protein (hs-CRP) in Japanese subjects. Intern Med. 2011;50:2767-73.

27. Vague $P$, Juhan-Vague I, Chabert V, Alessi MC, Atlan C. Fat distribution and plasminogen activator inhibitor activity in nondiabetic obese women. Metabolism. 1989;38:913-5.

28. Landin K, Stigendal L, Eriksson E, et al. Abdominal obesity is associated with an impaired fibrinolytic activity and elevated plasminogen activator inhibitor-1. Metabolism. 1990;39:1044-8.

29. Loskutoff DJ, Samad F. The adipocyte and hemostatic balance in obesity: studies of PAI-1. Arterioscler Thromb Vasc Biol. 1998;18:1-6.

30. Alessi MC, Peiretti F, Morange P, Henry M, Nalbone G, Juhan-Vague I. Production of plasminogen activator inhibitor 1 by human adipose tissue: possible link between visceral fat accumulation and vascular disease. Diabetes. 1997;46:860-7.

31. Folsom AR, Qamhieh HT, Wing RR, et al. Impact of weight loss on plasminogen activator inhibitor (PAI-1), factor VII, and other hemostatic factors in moderately overweight adults. Arterioscler Thromb. 1993;13:162-9.

32. Mavri A, Stegnar M, Krebs M, Sentocnik JT, Geiger M, Binder BR. Impact of adipose tissue on plasma plasminogen activator inhibitor-1 in dieting obese women. Arterioscler Thromb Vasc Biol. 1999;19:1582-7.

33. Sylvan A, Rutegard JN, Janunger KG, Sjolund B, Nilsson TK. Normal plasminogen activator inhibitor levels at long-term follow-up afte jejuno-ileal bypass surgery in morbidly obese individuals. Metabolism. 1992;41:1370-2

34. Fu Y, Luo N, Klein RL, Garvey WT. Adiponectin promotes adipocyte differentiation, insulin sensitivity, and lipid accumulation. J Lipid Res. 2005;46:1369-79.

35. Pajvani UB, Scherer PE. Adiponectin: systemic contributor to insulin sensitivity. Curr Diab Rep. 2003;3:207-13.

36. Yamauchi T, Kamon J, Waki H, et al. The fat-derived hormone adiponectin reverses insulin resistance associated with both lipoatrophy and obesity. Nat Med. 2001;7:941-6.

37. Lindsay RS, Funahashi T, Hanson RL, et al. Adiponectin and development of type 2 diabetes in the Pima Indian population. Lancet. 2002;360:57-8.

38. Karelis AD, St-Pierre DH, Conus F, Rabasa-Lhoret R, Poehlman ET. Metabolic and body composition factors in subgroups of obesity: what do we know? J Clin Endocrinol Metab. 2004;89:2569-75.

39. Farb MG, Bigornia S, Mott M, et al. Reduced adipose tissue inflammation represents an intermediate cardiometabolic phenotype in obesity. J Am Coll Cardiol. 2011;58:232-7.

40. Ganz ML, Wintfeld N, Li Q, Alas V, Langer J, Hammer M. The association of body mass index with the risk of type 2 diabetes: a case-control study nested in an electronic health records system in the United States. Diabetology \& metabolic syndrome. 2014;6:50.

\section{Submit your next manuscript to BioMed Central and we will help you at every step:}

- We accept pre-submission inquiries

- Our selector tool helps you to find the most relevant journal

- We provide round the clock customer support

- Convenient online submission

- Thorough peer review

- Inclusion in PubMed and all major indexing services

- Maximum visibility for your research

Submit your manuscript at www.biomedcentral.com/submit
() BioMed Central 